\title{
The rise and fall of the biopsychosocial model
}

\section{S. Nassir Ghaemi}

\section{Summary}

The biopsychosocial model is the conceptual status quo of contemporary psychiatry. Although it has played an important role in combatting psychiatric dogmatism, it has devolved into mere eclecticism. Other non-reductionistic approaches to medicine and psychiatry such as William Osler's medical humanism or Karl Jaspers' method-based psychiatry should be reconsidered.

\section{Declaration of interest}

In the past 12 months, D.G. has received a research grant from Pfizer and honoraria from Bristol-Myers Squibb and AstraZeneca. Neither he nor his family hold equity positions in pharmaceutical corporations.
S. Nassir Ghaemi (pictured), Professor of Psychiatry at Tufts University, is author of The Concepts of Psychiatry and the forthcoming book The Rise and Fall of the Biopsychosocial Model.

\section{The conceptual status quo}

The mainstream ideology of contemporary psychiatry is the biopsychosocial model. Many, who see psychiatry as too biological, advocate greater fealty to this model. The 'medical model' has few supporters in daylight. ${ }^{1}$ Compared with the medical model, some (like George Engel) see the biopsychosocial model as more scientific (including psychosocial sciences); ${ }^{2}$ others see it as more pragmatic or humanistic. Unhappiness about biological psychiatry partly involves reaction to 'evidence-based' practice, used by pharmaceutical and insurance industries or national health plans to favour pharmacological over psychosocial interventions. The biopsychosocial model is seen as an antidote, yet it might equally be a cause, failing to provide convincing conceptual or empirical grounds to resist the biologisation of psychiatry. The problem exists, perhaps, in a failure of the model itself, not failure to implement it, as many presume.

The model's claim, in the words of its founder Engel, is that 'all three levels, biological, psychological, and social, must be taken into account in every health care task. ${ }^{3}$ No single illness, patient or condition can be reduced to any one aspect. They are all, more or less equally, relevant, in all cases, at all times.

\section{Origins}

History is relevant: with roots in psychosomatic medicine (founded by Franz Alexander, a student of Freud), Engel was trying to psychologise medicine (current biopsychosocial proponents seek to avoid medicalising psychiatry). An internist, trained in psychoanalysis with Alexander, Engel was a specialist in functional gastrointestinal disorders (especially ulcerative colitis). Engel focused on medical, not psychiatric, illnesses. In his classic articles, he describes patients with myocardial infarction or gastrointestinal illness, not mental illness. He did not distinguish the two: he believed the model would apply in all illness, but he never tried to show its relevance to mental illness; he assumed it.

The biopsychosocial concept was around in the 1950s: Roy Grinker (a neurologist and psychiatrist analysed by Freud, and later a member of Alexander's group) actually coined the term 'biopsychosocial' long before Engel (in 1954 v. 1977). ${ }^{4}$ Grinker applied it to psychiatry to emphasise the 'bio' against psychoanalytic orthodoxy; Engel applied it to medicine to emphasise the psychosocial. Grinker was forthright about the limits of the biopsychosocial approach: he discounted a 'unified field theory' for psychiatry, and rejected biopsychosocial-like holism for research where specificity is needed. Engel, on the other hand, claimed that the biopsychosocial model was a 'blueprint for research, a framework for teaching, and a design for action in the real world of health care'.

The biopsychosocial banner was raised in the USA around 1980, coincidentally with the rise of DSM-III and psychopharmacology, and the decline of psychoanalysis. Perhaps the biopsychosocial model was, as one historian suggests, a method to preserve psychoanalysis 'through the back door.' ${ }^{5}$ This interpretation is supported by recent biopsychosocial manuals, which overwhelmingly describe psychoanalytic concepts (like defence mechanisms) as part of the model's formulation, with scant attention given to biological or social features. ${ }^{6}$

\section{Eclecticism}

Beyond the formal definition given above, there is another ultimate, rarely explicit rationale for the biopsychosocial model: eclecticism. Grinker forthrightly argued for a 'struggle for eclecticism ${ }^{4}$ as opposed to psychoanalytic dogmatism. Yet where Grinker was sober and limited in his goals, Engel was expansive. Grinker identified the key: biopsychosocial advocates really seek eclectic freedom, the ability to 'individualise treatment to the patient', which has come to mean, in practice, being allowed to do whatever one wants to do. This eclectic freedom borders on anarchy: one can emphasise the 'bio' if one wishes, or the 'psycho' (which is usually psychoanalytical among many biopsychosocial advocates), or the 'social'. But there is no rationale why one heads in one direction or the other: by going to a restaurant and getting a list of ingredients, rather than a recipe, ${ }^{7}$ one can put it all together however one likes. This results in the ultimate paradox: free to do whatever one chooses, one enacts one's own dogmas (conscious or unconscious). Like a Hegelian tragedy, eclecticism produces dogmatism; anarchy leads to tyranny. Then all complain and ask for more freedom - more of the same model that led to the status quo in the first place.

\section{Defences}

Proponents of the biopsychosocial model may propose conceptual and empirical defences. One conceptual defence rests on the 
benefits of holism, as opposed to reductionism. Grinker and Engel took this approach using general systems theory in biology. ${ }^{2}$ The basic idea is that 'more is better': truth is achieved by adding more and more perspectives, getting closer and closer to a highly complex reality. This is common sense, perhaps, but not scientific sense. Reductionism is not always wrong; peptic ulcer disease, long considered a classic psychosomatic illness, proves to be caused by Helicobacter pylori. In a hallmark of science, the apparently complex proved to be simple.

Another conceptual defence sees the biopsychosocial model heuristically, reminding us to pay attention to three aspects of illness. Then the question becomes: how do we choose? How do we prioritise one aspect versus another? Some might propose that evidence-based medicine provides the mechanism of choice, but often evidence is limited or absent. The biopsychosocial model, as classically advanced, does not guide us on how to prioritise. Consequently, prioritisation happens on the run, with each person's own preferences, and the model devolves into mere eclecticism, passing for sophistication.

An empirical defence of 'the more is better' philosophy sometimes is made based on the eclectic biopsychosocial intuition that medications and psychotherapy are always, and inherently, more effective than either alone. Empirically, sometimes this is so, sometimes not. Using one method or treatment purely often produces better results or is more valid than using multiple approaches together.

\section{Alternatives}

Are these the only alternatives? Biomedical reductionism ('the medical model') or the biopsychosocial model; additive eclecticism (more is better) or dogmatism? The biopsychosocial approach only shines when opposed to straw men. Another alternative to dogmatism, besides additive eclecticism, is a method-based psychiatry, as advocated by Karl Jaspers. Another alternative to a 'cold and impersonal' biomedical model ${ }^{2}$ is a medical humanist model, as developed by William Osler. ${ }^{8}$

Jaspers, who realised that theories rose and fell with their methods, saw two major methods in psychiatry: the objective/ empirical $v$. the subjective/interpretive. Methodology determined the strengths and weaknesses of theories. Rather than advocating one or the other method, Jaspers called for methodological consciousness: we need to be aware of what methods we use, their strengths and limitations, and why we use them. ${ }^{9}$ Dogmatists hold that one method is sufficient, biopsychosocial eclectics that methods should always be combined, Jaspers that (depending on the condition) sometimes one, sometimes another, method is best. Many clinicians conflate the terms pluralistic ${ }^{9}$ and eclectic, so perhaps Jaspers' non-dogmatic, non-eclectic approach should be called method-based psychiatry (in analogy to evidence-based medicine).

Osler (modernising Hippocrates) argued that the physician's role was to treat disease in the body (biomedical reductionism) while attending to the human being, the person, who has the disease. Osler applied the medical model non-reductionistically. Where disease is present, one treats the body; where disease is ameliorable but not curable, one still treats with attention to risks; and where no disease exists (some patients have symptoms or signs, but no disease, e.g. cough, rather than pneumonia) one attends to the human being as a person. ${ }^{10}$ This approach (which captures the Hippocratic aim: to cure sometimes, to heal often, to console always), has all the strengths and none of the weaknesses of the biopsychosocial model.

Osler taught that medicine is an art based on science; not simply a science, but also not merely an art. Engel explicitly rejected the concept of an art of medicine, arguing that it denigrated psychosocial factors into idiosyncratic interpersonal skills. Osler viewed the science of medicine as biological and the art as humanistic: he thus advocated learning about human beings from classic sources, literature and poetry - the humanities; Engel explicitly rejected this view. ${ }^{2}$ Engel's biopsychosocial model is, in this sense, anti-humanistic. Medicine strides the famous dichotomy between science and the humanities: Osler tried to bridge it with medical humanism, Engel through psychologised scientism.

\section{The future}

Perhaps new and improved biopsychosocial approaches, better than those of Engel or Grinker, will emerge, such as in social epidemiology and developmental biology/psychopathology. Although such efforts are laudable, it is unclear how they provide a new model for medicine or psychiatry, or how they improve upon medical humanism or Jaspersian method-based psychiatry.

The biopsychosocial model was valuable in its day as a reaction to biomedical reductionism, but its historical role has played out. Mental illness is complex; biology is not enough; but the biopsychosocial model does not thereby follow. Other less eclectic, less generic, less vague alternatives exist. Psychiatry would do well to look to them, rather than revisit an outworn label.

S. Nassir Ghaemi, MD, MPH, Tufts Medical Center, Department of Psychiatry, Box 1007, 800 Washington Street, Boston, MA 02111, USA. Email:

nghaemi@tuftsmedicalcenter.org

First received 15 Jan 2009, final revision 20 Mar 2009, accepted 24 Mar 2009

\section{References}

1 Craddock N, Antebi D, Attenburrow MJ, Bailey A, Carson A, Cowen P, et al. Wake-up call for British psychiatry. Br J Psychiatry 2008; 193: 6-9.

2 Engel GL. The need for a new medical model: a challenge for biomedicine. Science 1977; 196: 129-36.

3 Engel GL. The biopsychosocial model and the education of health professionals. Ann N Y Acad Sci 1978; 310: 169-87.

4 Grinker Sr RR. A struggle for eclecticism. Am J Psychiatry 1964; 121: 451-7.

5 Shorter E. The history of the biopsychosocial approach in medicine: before and after Engel. In Biopsychosocial Medicine: An Integrated Approach to Understanding IIlness (ed P White): 1-19. Oxford University Press, 2005.

6 Campbell W, Rohrbaugh R. The Biopsychosocial Formulation Manual. Routledge, 2006.

7 McHugh P, Slavney P. Perspectives of Psychiatry (2nd edn). Johns Hopkins University Press, 1998.

8 Osler W. Aequanimitas (3rd edn). The Blakiston Company, 1932

9 Ghaemi SN. The Concepts of Psychiatry: A Pluralistic Approach to the Mind and Mental Illness. Johns Hopkins University Press, 2007.

10 Ghaemi SN. Toward a Hippocratic psychopharmacology. Can J Psychiatry 2008; 53: 189-96. 